\title{
Phylogenetic analysis of the Saccharomyces cerevisiae group based on polymorphisms of rDNA spacer sequences
}

\author{
Robert Montrocher, ${ }^{1}$ Marie-Christine Verner, ${ }^{1}$ Jérôme Briolay, ${ }^{2}$ \\ Christian Gautier $^{2}$ and Roland Marmeisse ${ }^{1}$
}

Author for correspondence: Robert Montrocher. Fax: +33472431643 .

e-mail: rmontroc@lercycle.univ-lyonl.fr

CNRS, UMR 5557 'Ecologie Microbienne du Sol', Bât. 405', and Centre d'Analyse Moléculaire de la

Biodiversité2, Université Lyon 1, 43 boulevard du 11 Novembre 1918,69622 Villeurbanne Cedex, France
The phylogenetic relationships between species of yeasts assigned to the Saccharomyces sensu stricto group, which includes Saccharomyces cerevisiae and Saccharomyces bayanus, were studied together with Saccharomyces pastorianus and Saccharomyces paradoxus. The experimental approaches used were RFLP analysis of the PCR-amplified rDNA internal transcribed spacer (ITS) and intergenic spacer, and total ITS sequence analysis. Both RFLP and sequence analyses gave fairly similar results. The gene trees generated with either of the two data sets showed the distribution of the yeasts into two major, wellseparated, phylogenetic clusters called 'cerevisiae' and 'bayanus'. The 'cerevisiae' cluster included the $S$. cerevisiae type strain, together with most of the species (16 out of 23), whereas the 'bayanus' cluster included the remaining seven type strains. Therefore, analysis of rDNA sequences confirmed S. cerevisiae and S. bayanus as two well-defined taxa. However, $S$. pastorianus and S. paradoxus, the two other usually accepted taxa of the nowdefined Saccharomyces sensu stricto complex, could not be clearly separated from S. bayanus and S. cerevisiae, respectively. However, in both PCR-RFLP and ITS sequence analyses, $S$. paradoxus had the outermost position in the 'cerevisiae' cluster. PCR-RFLP analysis of the ribosomal spacer sequences was also carried out on 26 Saccharomyces strains isolated in various wine-growing regions of France in an attempt to clarify their positions in the Saccharomyces phylogenetic tree. Compared to the diversity of the Saccharomyces type strains, less genetic diversity was detected among these yeasts and several of them exhibited identical RFLP patterns. Most of the wine yeast strains (16 out of 26) were closely related to each other and were found within the 'cerevisiae' cluster. The remaining 10 wine yeast strains branched within the 'bayanus' cluster. PCR-RFLP analysis of ribosomal spacer sequences thus appears to be a useful and appropriate method for the correct characterization of Saccharomyces yeast strains used in food processing.

Keywords: Saccharomyces cerevisiae, PCR-RFLP analysis of rDNA, rDNA ITS sequence analysis, molecular phylogeny

\section{INTRODUCTION}

Conventional methods used for the identification of yeast species rely extensively on the study of physiological characteristics such as the ability of isolates to assimilate and/or ferment different carbon sources. As

Abbreviations: RAPD, randomly amplified polymorphic DNA; mtDNA, mitochondrial DNA; nDNA, nuclear DNA; ITS, internal transcribed spacer; IGS, intergenic spacer; $d$, molecular distance value. expected, closely related species may differ from each other by a very limited number of such characteristics which, for some of them, may be controlled by single mutable genes. This is the case within the genus Saccharomyces Meyen ex Reess and more particularly for species closely related to Saccharomyces cerevisiae, which have been classically identified on their varying abilities to use less than 10 different carbon sources (1). The extreme proximity between species within this group has led, in the past, to many different changes in 
Table 1. Saccharomyces sensu stricto type strains studied

\begin{tabular}{|c|c|c|c|c|c|c|}
\hline Species & CBS no. & Original name & Source & ITS type & IGS type & $\begin{array}{l}\text { ITS sequence } \\
\text { accession no. }\end{array}$ \\
\hline S. bayanus & $380^{\mathrm{T}}$ & S. bayanus & Beer & I & I & Z95945 \\
\hline S. bayanus & $395^{\mathrm{T}}$ & S. uvarum & Currant juice & I & II & Z95946 \\
\hline S. cerevisiae & $1171^{\mathrm{T}}$ & S. cerevisiae & Beer & VI & VI & \\
\hline S. cerevisiae & $4054^{\mathrm{T}}$ & S. aceti & Red wine & XII & XII & Z95931 \\
\hline S. cerevisiae & $2247^{\mathrm{T}}$ & S. capensis & Grape must & VII & XI & Z95937 \\
\hline S. cerevisiae & $400^{T}$ & S. chevalieri & Palm wine & $X V$ & XIII & Z95939 \\
\hline S. cerevisiae & $5635^{\mathrm{T}}$ & S. coreanus & Grape must & XV & XVII & Z95942 \\
\hline S. cerevisiae & $1782^{\mathrm{T}}$ & S. diastaticus & Infected wort & $\mathrm{X}$ & XVI & Z95935 \\
\hline S. cerevisiae & $6006^{\mathrm{T}}$ & S. gaditensis & Wine & V & $\mathrm{X}$ & Z95951 \\
\hline S. bayanus & $424^{\mathrm{T}}$ & S. globosus & Pear juice & IV & I & Z95947 \\
\hline S. bayanus & $425^{\mathrm{T}}$ & $S$. heterogenicus & Apple juice & III & I & Z95944 \\
\hline S. cerevisiae & $4903^{T}$ & S. hienipiensis & 'Alpechin' & $\mathrm{XV}$ & XIV & Z95940 \\
\hline S. bayanus & $1546^{\mathrm{T}}$ & S. inusitatus & Beer & I & I & Z95948 \\
\hline S. cerevisiae & $459^{\mathrm{T}}$ & S. italicus & Grape must & $\mathrm{XV}$ & VII & Z95938 \\
\hline S. cerevisiae & $382^{\mathrm{T}}$ & S. logos & Beer & XI & VIII & Z95936 \\
\hline S. cerevisiae & $5378^{\mathrm{T}}$ & S. norbensis & 'Alpechin' & $\mathrm{XV}$ & XVII & Z95929 \\
\hline S. cerevisiae & $3093^{T}$ & S. oleaceus & Olives & XIV & XVII & Z95943 \\
\hline S. cerevisiae & $3081^{\mathrm{T}}$ & S. oleaginosus & 'Alpechin' & $\mathrm{XV}$ & XVII & Z95941 \\
\hline S. cerevisiae & $5155^{\mathrm{T}}$ & S. prostoserdovi & Wine & VIII & IX & Z95934 \\
\hline S. cerevisiae & $423^{\mathrm{T}}$ & S. steineri & Grape must & XIII & $X V$ & Z95932 \\
\hline S. paradoxus & $432^{\mathrm{T}}$ & S. paradoxus & & IX & V & Z95933 \\
\hline S. pastorianus & $1538^{\mathrm{T}}$ & S. pastorianus & & II & III & Z95949 \\
\hline S. pastorianus & $1513^{\mathrm{T}}$ & S. carlsbergensis & Beer & II & IV & Z95950 \\
\hline
\end{tabular}

their taxonomic status. The originally 21 recognized species of the Saccharomyces sensu stricto group (33) were grouped by Yarrow (40) in a single taxon: $S$. cerevisiae. According to Vaughan Martini \& Martini (37), S. cerevisiae sensu Yarrow has now been split into three species: S. cerevisiae, Saccharomyces bayanus and Saccharomyces pastorianus which constitute, together with Saccharomyces paradoxus (35), the Saccharomyces sensu stricto complex. Furthermore, studies of the genes whose enzyme products allow the cells to utilize some of the carbon sources classically used for species identification show that the number and location of these genes in the genome can vary between strains of the same species. This is, for example, the case of the MEL genes (controlling melibiose fermentation) which can either be absent or present in one or multiple copies in the genomes of $S$. cerevisiae strains (20). This situation, which is also found for other yeast genes whose products protect the cells against toxic compounds (22), may reflect the adaptation of strains to local environmental conditions but not their taxonomic status.

The criterion originally used to separate the four above-mentioned species ( $S$. cerevisiae, $S$. bayanus, $S$. pastorianus and $S$. paradoxus) was DNA relatedness, as measured in whole-cell DNA/DNA reassociation experiments $(35,36,37)$. This classification was further substantiated by many other studies on electrophoretic karyotypes $(2,8,18,38)$, mitochondrial DNA (mtDNA) restriction endonuclease profiles (5), rDNA restriction analysis (12), analysis of randomly amplified polymorphic DNAs (RAPDs) (13), and by studies which showed that interspecific hybrids between these species, although viable, gave abortive ascospores (14).

Most of these studies were intended to identify the four different species and to classify different wild or industrial strains of Saccharomyces. Few of these studies (mtDNA and RAPD) allow a clear understanding of the phylogenetic relationships between these four different species. In this article, RFLP analysis and sequencing of nuclear rDNA spacers were carried out on the 21 original Saccharomyces species pooled by Yarrow (40) in one taxon. These data were used to infer phylogenetic trees. RFLP analysis was also carried out on 26 wine yeast strains to clarify their positions in the Saccharomyces phylogenetic tree.

In $S$. cerevisiae, as in most fungal species, the four different rDNA genes (5S, 5.8S, $18 \mathrm{~S}$ and $26 \mathrm{~S}$ ) are grouped in repeats which are arranged head-to-tail to form a single cluster on chromosome XII. The $18 \mathrm{~S}$ and $26 \mathrm{~S}$ genes are separated from each other by the internal transcribed spacers (ITS) and intergenic spacers (IGS), which are non-coding sequences except for the short $5.8 \mathrm{~S}$ and $5 \mathrm{~S}$ genes, respectively. Both these spacer sequences can easily be amplified by PCR using oligonucleotide primers homologous to sequences present at the ends of the rDNA genes (39). A model of the secondary folding structure of the ITS sequence from $S$. cerevisiae has been obtained; this sequence has been divided into several structural domains, each 
characterized by one or two loops (27). Interestingly, the sequences of ITS regions from related yeast species could be only partially aligned to the ITS sequence of $S$. cerevisiae (34), thus making this sequence a good candidate for the study of the molecular phylogeny of closely related yeast species.

\section{METHODS}

Yeast strains. The characteristics of the 49 strains studied are given in Tables 1 and 2. Twenty-three of them are the type strains of the species recognized by van der Walt (Table 1). Twenty-six are wine yeast strains collected in different regions of France (provided by C. Cuinier, ITV, Tours, France) (Table 2).

PCR-RFLP analysis. DNA was extracted from $5 \mathrm{ml}$ yeast liquid cultures according to the method of Phillipsen et al. (25). Amplifications of the target sequences were carried out in a $50 \mu$ volume containing $1-10 \mathrm{ng}$ genomic DNA, $100 \mathrm{nM}$ of each primer, $200 \mu \mathrm{M}$ of each of the four dNTPs, $1 \mathrm{U} \mathrm{Taq}$ DNA polymerase and the appropriate buffer supplied by the manufacturer (Appligène). The primers used to amplify the ITS sequences were 3126T (5'-ATATGCTTAAGTTCAGCGGGT-3'), which hybridized to the $5^{\prime}$ end of the $26 \mathrm{~S}$ gene, and 2234C (5'-GTTTCCGTAGGTGAACCTGC-3'), which hybridized to the $3^{\prime}$ end of the $18 \mathrm{~S}$ gene (31). The primers used to amplify the IGS sequences were 126 (5'-ACCAC-
CTAGGACGGTCATCA-3'), which hybridized to the $3^{\prime}$ end of the 26S gene, and 127 (5'-GTAGAGTAGCCTTGTTGTTACGATC- $3^{\prime}$ ), which hybridized to the $5^{\prime}$ end of the $18 \mathrm{~S}$ gene (4). For the ITS, after an initial denaturation at $95^{\circ} \mathrm{C}$ for $2 \mathrm{~min}$, the sequence was amplified by 35 cycles of $1 \mathrm{~min}$ at $95^{\circ} \mathrm{C}, 1 \mathrm{~min}$ at $50^{\circ} \mathrm{C}$, and $1 \mathrm{~min}$ at $72^{\circ} \mathrm{C}$; this was followed by a final extension of $2 \mathrm{~min}$ at $72^{\circ} \mathrm{C}$. For the IGS, after an initial denaturation at $95^{\circ} \mathrm{C}$ for $3 \mathrm{~min}$, the sequence was amplified by 37 cycles of $2 \mathrm{~min}$ at $95{ }^{\circ} \mathrm{C}, 1 \mathrm{~min}$ at $55^{\circ} \mathrm{C}$, and $3 \mathrm{~min}$ at $72^{\circ} \mathrm{C}$; this was followed by a final extension of $7 \mathrm{~min}$ at $72{ }^{\circ} \mathrm{C}$. Appropriate amounts of the amplified sequences were digested with the four-cutter enzymes $A l u \mathrm{I}$, Bst UI, CfoI, DdeI, HaeIII, HpaII, NdeII, RsaI and TaqI, and HinfI which has a 5 bp recognition site. Restriction fragments were separated by electrophoresis in $8 \%$ polyacrylamide gels for the ITS and in 3\% agarose gels [2\% NuSieve agarose (FMC Bioproducts), $1 \%$ agarose (Appligène)]. After electrophoresis, the gels were stained with ethidium bromide and photographed. For the ITS, only the restriction fragments larger than the $100 \mathrm{bp}$ pBR322 HinfI size marker were recorded; for the IGS, only those larger than the 75 bp pBR322 HinfI size marker were recorded.

The relationships between the amplified sequences of the different Saccharomyces strains were evaluated by their fraction $(F)$ of co-migrating fragments $\left[F=2 n_{\mathrm{xv}} /\left(n_{\mathrm{x}}+n_{\mathrm{y}}\right)\right.$, where $n_{\mathrm{xy}}$ is the number of co-migrating bands and $n_{\mathrm{x}}$ and $n_{\mathrm{y}}$

Table 2. Origin and characteristics of the Saccharomyces wine yeast strains studied

\begin{tabular}{|c|c|c|c|c|c|}
\hline Species* & Original name and ITV no. $\dagger$ & $\begin{array}{l}\text { No. in } \\
\text { Fig. } 1\end{array}$ & Origin $\S$ & ITS type & IGS type \\
\hline S. bayanus & S. uvarum L1708 & 1 & Sancerrois, 1986 & I & XVIII \\
\hline S. cerevisiae & S. bayanus L3336 & 2 & Touraine, 1981 & XVII & XXII \\
\hline S. cerevisiae & S. uvarum L579 & 3 & Beaujolais, 1986 & XV & XXI \\
\hline S. cerevisiae & S. bayanus L3571 & 4 & Savoie, 1987 & $X V$ & XXI \\
\hline S. bayanus & S. uvarum L19 & 5 & Touraine, 1978 & I & XVIII \\
\hline S. bayanus & S. uvarum L99 & 7 & Touraine, 1975 & I & XVIII \\
\hline S. bayanus & S. uvarum L490 & 8 & Touraine, 1982 & I & XVIII \\
\hline S. cerevisiae & S. uvarum L1425 & 10 & Beaujolais, 1986 & $X V$ & XXI \\
\hline S. cerevisiae & S. cerevisiae L1642 & 11 & Sancerrois, 1986 & $X V$ & $\mathrm{XX}$ \\
\hline S. bayanus & S. uvarum L3583 & 12 & Savoie, 1987 & XVI & XVIII \\
\hline S. cerevisiae & S. bayanus L206 & 13 & Beaujolais, 1986 & XVIII & XXI \\
\hline S. cerevisiae & S. cerevisiae L1656 & 14 & Charentes, 1986 & $\mathrm{XV}$ & XXI \\
\hline S. cerevisiae & S. bayanus L541 & 15 & Beaujolais, 1985 & XVIII & XXI \\
\hline S. cerevisiae & S. bayanus L601 & 16 & Beaujolais, 1985 & $\mathrm{XV}$ & XXI \\
\hline S. bayanus & S. uvarum L259 & 17 & Touraine, 1975 & I & XVIII \\
\hline S. cerevisiae & S. cerevisiae L2835 & 18 & Beaujolais, 1984 & $\mathrm{XV}$ & XXI \\
\hline S. cerevisiae & S. cerevisiae L649 & 19 & Beaujolais, 1985 & $X V$ & XXI \\
\hline S. cerevisiae & S. cerevisiae L3587 & 21 & Savoie, 1987 & $X V$ & XXI \\
\hline S. cerevisiae & S. cerevisiae L3380 & 22 & Côtes du Rhône, 1981 & $\mathrm{XV}$ & XIX \\
\hline S. cerevisiae & S. bayanus L2006 & 24 & Touraine, 1977 & $X V$ & XXI \\
\hline S. bayanus & S. uvarum L85 & 25 & Alsace, 1988 & I & XVIII \\
\hline S. cerevisiae & S. uvarum L2784 & 26 & Beaujolais, 1984 & $X V$ & $\mathrm{XX}$ \\
\hline S. bayanus & S. pretoriensis L3304 & 27 & Touraine, 1981 & I & XVIII \\
\hline S. bayanus & S. uvarum L1609 & 28 & Touraine, 1986 & I & XVIII \\
\hline S. cerevisiae & S. bayanus L1392 & 29 & Touraine, 1985 & XVII & XXII \\
\hline S. bayanus & S. cerevisiae L926 & 30 & Touraine, 1985 & I & XVIII \\
\hline
\end{tabular}

* Species as defined in this study.

$\dagger$ ITV, Institut Technique de la Vigne et du Vin, Tours, France.

$\S$ Wine-growing regions of France. 
are the number of bands of strain $\mathrm{x}$ and strain $\mathrm{y}$, respectively]. Molecular distances (d) were then estimated using the mathematical model of Nei \& Li (21). Cluster analysis of these $d$ values was performed using the neighbour-joining method (29). The calculations were performed using a hypercard compilation running on a Macintosh computer (Marc Neyra; ORSTOM, Dakar; Ecologie Microbienne CNRS, Lyon, France; unpublished).

Sequencing and data analysis. The ITS sequences were amplified by using the PCR conditions described above. The amplified products were purified and concentrated on Centricon columns (Amicon). The purified double-stranded PCR products were directly used for sequencing using the T7 sequencing kit from Pharmacia LKB based on the dideoxy chain-termination method (30) according to J. Briolay and others (unpublished). To sequence both strands, seven primers were used: $2234 \mathrm{C}$ and $3126 \mathrm{~T}$ as described above; and AM2541 (5'-GCATCGATGAAGAACGCAGC-3'), AM2542 (5'-GCTGCGTTCTTCATCGATGC-3'), AM454 (5'-TCACTCACTACCAAACAGAA-3'), AM1701 (5'-TTTCCTTCTCAAACATTCTG-3') and AM3393 (5'-CCTTACGGGTTTCTTTTTCAA-3'), which were deduced from the published sequence of the $S$. cerevisiae HA6 strain (GenBank accession no. U09327).

Sequences were aligned using CLUSTAL w (32) and manually refined using SEAVIEW (3). All regions corresponding to a gap in one sequence were excluded from the analyses. Matrix pairwise comparisons were corrected for multiple base substitutions by the two-parameter model of Kimura (10) and a phylogenetic tree was generated by the neighbourjoining method using PHYLO-WIN (3). Bootstrap analysis (1000 replications) was performed to assess the strength of the internal branches of the tree.

\section{RESULTS}

\section{PCR-RFLP analysis of the rDNA spacers}

The ITS and IGS sequences were amplified from the genomic DNA of all 49 studied yeast strains. In all cases, a single DNA fragment was amplified and, for each of these two DNA regions, no significant size variation could be detected between strains after agarose gel electrophoresis. The amplified ITS and IGS were approximately $780 \mathrm{bp}$ and $3.2 \mathrm{~kb}$ long, respectively.

For the ITS, four of the 10 enzymes used ( $A l u \mathrm{I}, B s t \mathrm{UI}$, DdeI and HpaII) did not reveal any polymorphism between strains. Each of the six other enzymes gave variable numbers of restriction profiles, from four for $N d e I I$ and $C f o$ I to six for HinfI. After the restriction profiles produced by the different enzymes had been combined, 18 different ITS-RFLP types were distinguished. Several of the ITS of different strains were identical in this analysis. This was observed with ITS type XV, which was common to six different type strains (Table 1) and 12 wine yeast strains (Table 2). Interestingly, only five different ITS profiles characterized the 26 wine strains (Table 2) while 15 different ITS patterns were recorded amongst the Saccharomyces type strains (Table 1). Thirteen strains were each characterized by a unique set of restriction profiles; among them was $S$. cerevisiae CBS1171 type strain which was the only one to have unique HaeIII and
RsaI ITS profiles. RFLP analysis of this spacer sequence yielded 41 different restriction fragments, of which $35(85 \%)$ were polymorphic.

The $3 \cdot 2 \mathrm{~kb}$ IGS sequences were more polymorphic. All 10 restriction enzymes tested gave several restriction patterns, from four for HinfI to 12 for AluI. However, some of the strains could still not be distinguished from each other. This was particularly the case among the 26 wine yeast strains for which five sets of restriction patterns were recorded; two of these sets (IGS types XVIII and XXI) characterized 10 and 11 strains, respectively (Table 2). This is in contrast with the 23 Saccharomyces sensu stricto type strains which were distributed in 17 different IGS classes (Table 1). Interestingly, the $S$. cerevisiae CBS1171 type strain was the only strain which had a unique IGS restriction profile for each of the 10 enzymes used. RFLP analysis of the IGS yielded 184 different restriction fragments, of which $170(92 \%)$ were polymorphic.

Data from RFLP analyses of the ITS and IGS sequences were pooled and used to calculate pairwise $d$ values between the spacer sequences according to the model of Nei \& Li (21). The matrix of $d$ values was used to construct an inferred gene tree using the neighbour-joining method. This tree was characterized by two groups of phylogenetically close sequences, one of which was called the 'cerevisiae' cluster and the other, the 'bayanus' cluster (Fig. 1). The 'cerevisiae' cluster included most of the studied yeasts, i.e. 15 out of the 23 type strains plus 16 out of the 26 wine yeast strains. Within this cluster, the rDNA spacers were highly similar with a maximum $d$ value $\left(d_{\max }\right)$ between them of 0.033 substitutions per site. The only exception was the $S$. cerevisiae rDNA spacers, which were more distantly related to the other sequences; minimum $d$ value $\left(d_{\text {min }}\right)$ of 0.033 to Saccharomyces aceti and $d_{\max }$ of 0.056 to Saccharomyces chevalieri. The 'bayanus' cluster included the remaining yeasts except for $S$. paradoxus, i.e. seven type strains and 10 wine yeast strains (seven of which originated from the Touraine region of France). As observed for the 'cerevisiae' cluster, most of the sequences of the yeast type strains, including $S$. bayanus, were highly similar $\left(d_{\max }\right.$ of 0.009). The sequence of the Saccharomyces uvarum type strain was loosely linked to the latter type strains ( $d_{\min }$ of 0.063 to Saccharomyces heterogenicus). The rDNA spacers of the wine yeast strains included in this cluster were more related to the $S$. uvarum spacers $\left(d_{\max }\right.$ of 0.034$)$ than to the spacers of the other type strains. The two clusters 'cerevisiae' and 'bayanus' were clearly separated in this PCR-RFLP analysis, the $d_{\min }$ and $d_{\max }$ values separating the spacer sequences present in the two clusters were, respectively, 0.066 (Saccharomyces oleaceus/S. uvarum) and 0.101 (S. cerevisiae/Saccharomyces globosus). The rDNA spacers of Saccharomyces paradoxus had a somewhat intermediate position between the two clusters, being closer to the 'cerevisiae' cluster ( $d_{\min }$ of 0.057 to $S$. oleaceus) than to the 'bayanus' cluster ( $d_{\min }$ of 0.085 to Saccharomyces carlsbergensis). This intermediate pos- 


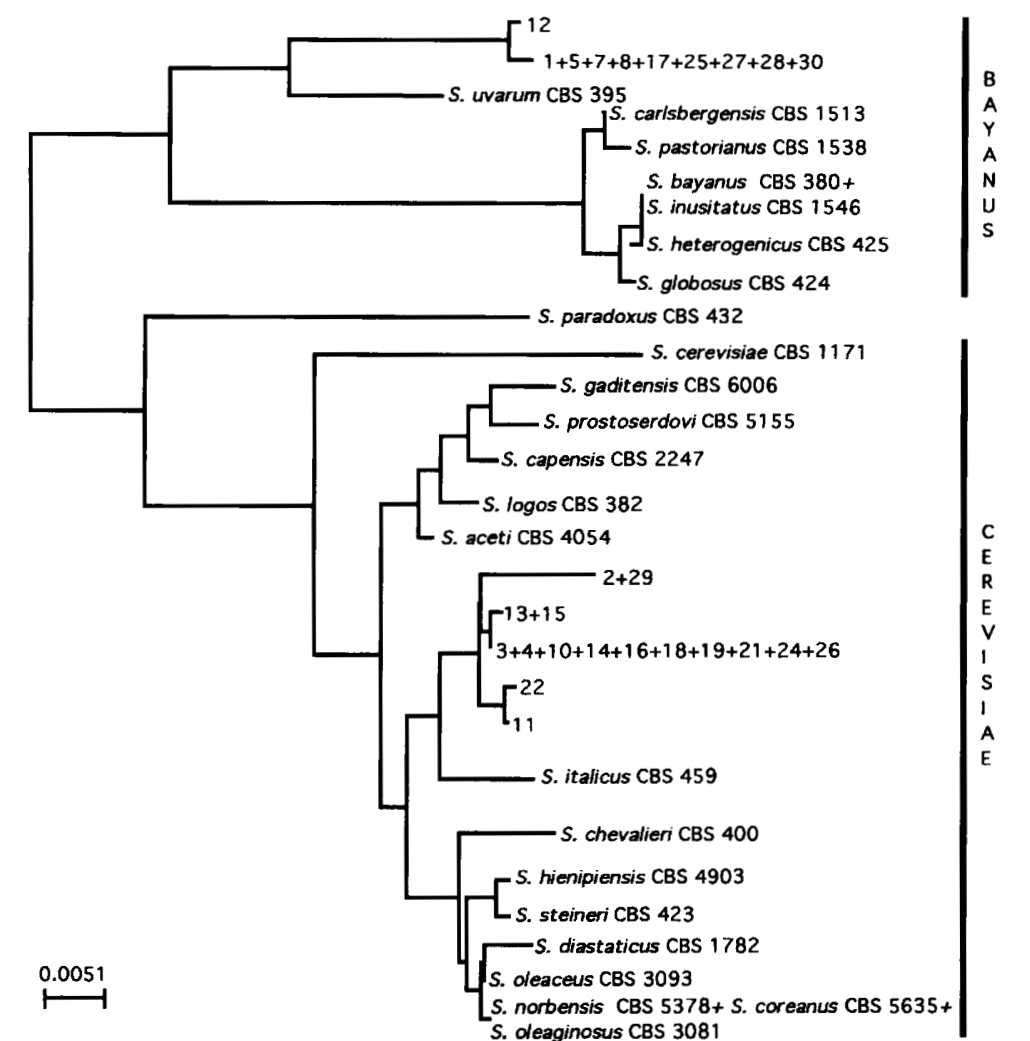

Fig. 1. Unrooted phylogenetic dendrogram showing the taxonomic positions of Saccharomyces type strains and wine yeast strains, based on the PCR-RFLP study of the ITS and IGS rDNA spacers. Numbers refer to strains listed in Table 2. Bar, $d$ value of 0.0051 .

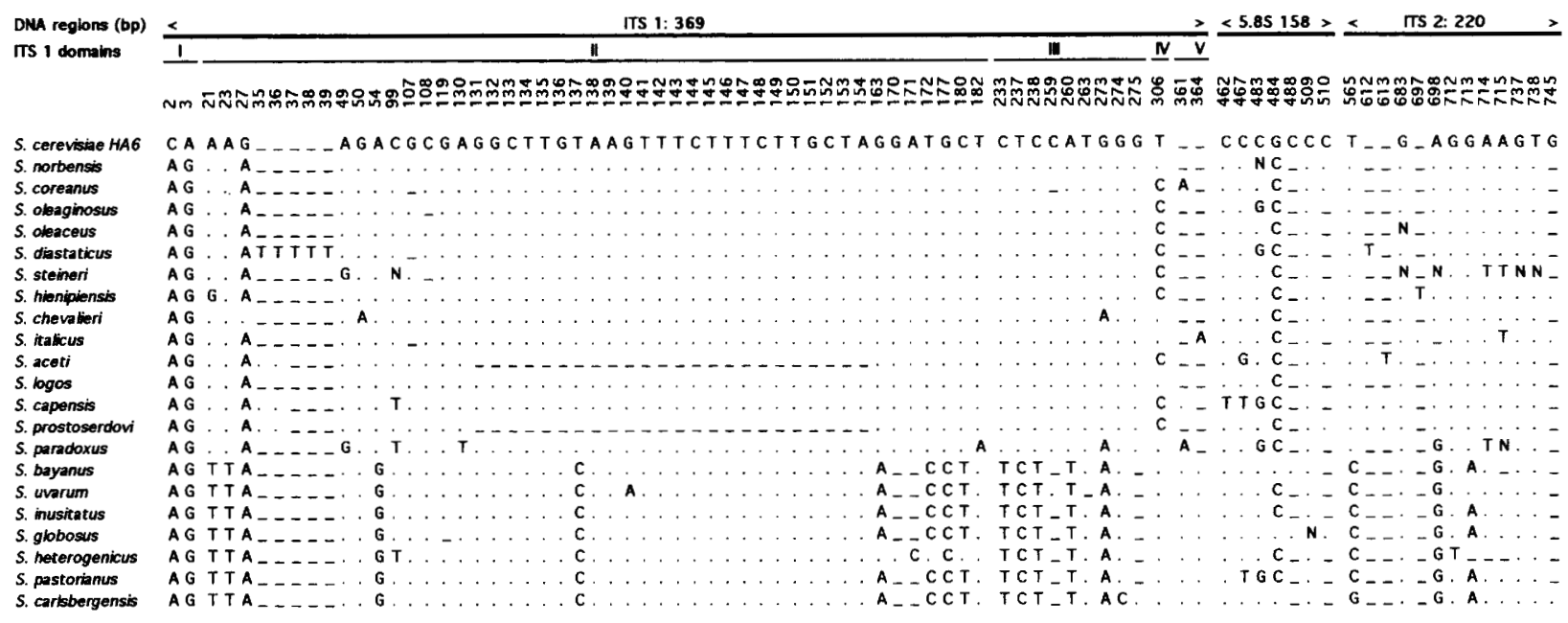

Fig. 2. Variable nucleotide positions within the ITS1-5.8S-ITS2 region of 21 Saccharomyces type strains (Table 1) compared to the corresponding sequence of the S. cerevisiae HA6 strain (GenBank accession no. U09327). Hyphens indicate deletions; $\mathrm{N}$, uncertain nucleotides.

ition of $S$. paradoxus resulted only from polymorphisms in the IGS; a tree based on only the ITS included S. paradoxus in the 'cerevisiae' cluster (results not shown).

\section{Sequence analysis of the ITS regions}

This was carried out on the 23 type strains. Repeated attempts to sequence the PCR-amplified ITS of $S$. cerevisiae CBS1171 type strain always gave several bands at most nucleotide positions suggesting that different sequences had been co-amplified by PCR. This strain was not studied further and the ITS sequence of $S$. cerevisiae strain HA6 (GenBank accession no. U09327) was used for comparison instead. The entire sequences of the ITS1 and 5.8S and the sequence of ITS2, excluding the last 10 nucleotides, were obtained for all other strains except Saccharomyces gaditensis for which the first 19 nucleotides of ITS 1 and the last 150 nucleotides of ITS 2 could not be 


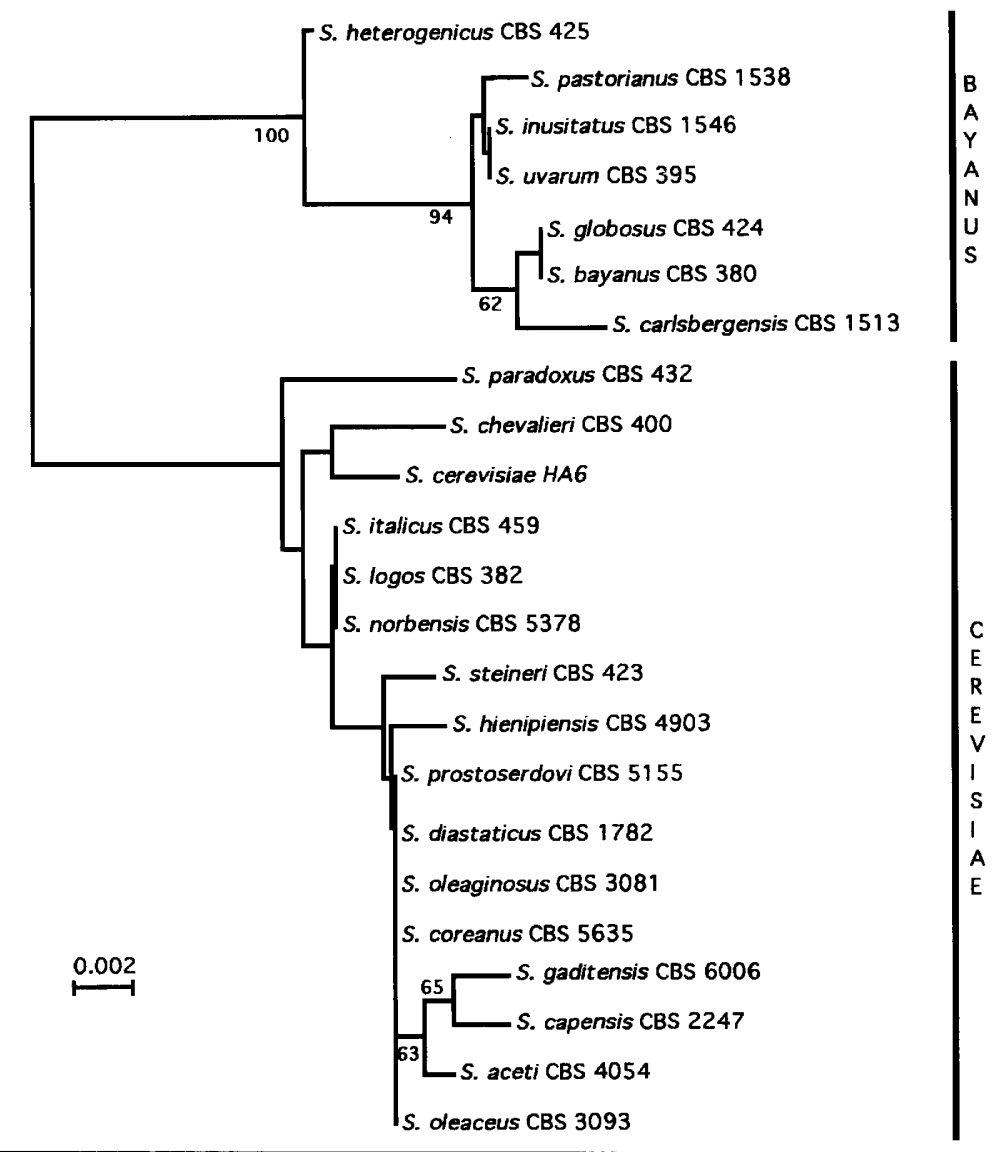

Fig. 3. Unrooted phylogenetic dendrogram showing the taxonomic positions of Saccharomyces type strains, based on the ITS1-5.8S-ITS2 sequences. Bootstrap supports higher than $60 \%$ are displayed. Bar, $d$ value of 0.002 .

read. If we exclude this latter strain, a total of 747 nucleotides including the $5.8 \mathrm{~S}$ gene, representing the full-length sequences, could be aligned without any ambiguities. Only $8 \mathrm{bp}$ were not read in the different sequences (Fig. 2). Several sequences had 1-5 bp insertions at various positions; three sequences (those of $S$. aceti, S. gaditensis and Saccharomyces prostoserdovi) shared an identical $24 \mathrm{bp}$ deletion between nucleotides 131 and 154 in ITS1. Most of the variable nucleotide positions were within ITS1 (39 out of a total of about 369 nucleotides) while ITS2 was less variable (10 variable positions out of about 220 nucleotides). The 5.8S gene was the most conserved part of the sequence with six variable positions out of 157 nucleotides (Fig. 2). Within ITS1, the variable positions were not evenly distributed; most were found in domains II and III $(12.6$ and $13.7 \%$, respectively, of variable positions) while domains IV and $\mathrm{V}$ were more conserved $(2 \cdot 1$ and $5.5 \%$, respectively, of variable positions).

The sequence alignment was used to construct an inferred phylogenetic tree by the neighbour-joining method (Fig. 3). For the calculation, 26 variable positions were considered. Inclusion or exclusion of the partial sequence of $S$. gaditensis in the calculation did not significantly change the topology of the tree and the bootstrap values of the nodes (results not shown). This comparative sequence analysis clearly showed the distribution of Saccharomyces type strains
ITS sequences into two major clusters which were called 'bayanus' and 'cerevisiae'. Within the 'bayanus' cluster, which included the ITS of seven type strains among which were those of $S$. bayanus and $S$. pastorianus, the different sequences were highly homologous with a $d_{\text {max }}$ between two sequences of 0.0117 ( $S$. carlsbergensis/S. heterogenicus). The 'cerevisiae' cluster included the other 16 type strain sequences among which were those of $S$. cerevisiae HA6 and $S$. paradoxus. The $d_{\max }$ within this group was 0.0137 ( $S$. paradoxus/Saccharomyces capensis).

The 'bayanus' and 'cerevisiae' clusters were clearly separated; the $d_{\min }$ between sequences in these two groups was 0.0196 (S. heterogenicus/Saccharomyces logos, Saccharomyces norbensis, Saccharomyces italicus). Furthermore, the two nodes between these two groups were separated by a high bootstrap value of $100 \%$ (Fig. 3). Although the S. paradoxus ITS sequence branched outside the 'cerevisiae' cluster, this node was not supported by a significant bootstrap value and therefore the sequence was not excluded from the 'cerevisiae' cluster.

\section{DISCUSSION}

Several studies on yeast strains belonging to Saccharomyces cerevisiae sensu Yarrow, especially those relative to nuclear DNA (nDNA)/nDNA reassociations (35, 37) have established that this species was genetically 
heterogeneous and consisted of four distinct sibling taxa: S. cerevisiae, $S$. bayanus, $S$. pastorianus and $S$. paradoxus. In this paper, analysis of the intergenic rDNA spacers of different yeast strains belonging to the Saccharomyces sensu stricto group (33) has revealed sequence polymorphisms which allow inference of the phylogenetic links existing between the sequences analysed. Both combined PCR-RFLP analysis of the ITS and IGS spacers and direct sequencing of the ITS lead to a similar grouping of the studied isolates, their rDNA spacer sequences being distributed in two wellseparated clusters called 'cerevisiae' and 'bayanus'. As for the sequences of $S$. paradoxus and $S$. pastorianus, they do not form separate clusters but instead are included in the 'cerevisiae' and 'bayanus' clusters, respectively.

The 'cerevisiae' cluster includes the sequences of 16 out of the 23 studied type strains. Yeasts within this cluster are those whose genomic DNAs showed a very high level of relatedness (more than $89 \%$ ) to the genomic DNA of the $S$. cerevisiae CBS1171 type strain (36). In RAPD analysis based on the use of three different 10 bp oligonucleotides, these strains appeared rigorously identical (13) whereas a certain amount of sequence polymorphism exists between their rDNA spacers.

The phylogenetic position of the $S$. paradoxus type strain relative to the other yeasts in the 'cerevisiae, cluster cannot clearly be established from our results. This species belongs to the cluster when considering only the ITS sequences, whereas it branches outside the cluster in the RFLP analysis, which takes into account polymorphisms in both the ITS and IGS spacers. This taxonomic proximity to the 'cerevisiae' cluster is consistent with the $\mathrm{nDNA} / \mathrm{nDNA}$ reassociation values reported between the two species (in the range $40-50 \%$ ), which are significantly higher than those reported with $S$. bayanus and $S$. pastorianus (34 and $23 \%$, respectively) $(35,36,37)$. The close phylogenetic relatedness between $S$. paradoxus and $S$. cerevisiae was also pointed out in two RFLP studies, one relative to the mitochondrial genome (5) and the other to the small- and large-subunit rRNA genes (11). Despite the similarities between these two species, interspecific crosses between monosporic isolates always gave hybrids producing non-viable ascospores $(15,17,19)$.

The 'bayanus' cluster includes the sequences of the seven remaining type strains. This group appears highly homogeneous as judged from the low $d$ values between the sequences. The only exceptions were $S$. uvarum and $S$. heterogenicus, which branched somewhat outside the cluster in only the PCR-RFLP study for the former and in only the ITS sequence analysis for the latter. Yeasts within the 'bayanus' cluster are those whose nDNA showed a high percentage (above $72 \%$ ) of reassociation to the nDNA of the S. bayanus type strain $(35,36)$. Nevertheless, the 'bayanus' cluster as defined in our study includes two of the recognized species of the $S$. cerevisiae complex, namely S. bayanus and $S$. pastorianus $(35,37) . S$. pastorianus is assumed to be a rare natural hybrid between $S$. cerevisiae and $S$. bayanus as its $\mathrm{nDNA}$ reassociates at a significant level to the DNAs of both these species (53 and $72 \%$, respectively) (35). It appears that the rDNA types of $S$. pastorianus and of its synonym $S$. carlsbergensis are both extremely similar to that of $S$. bayanus, thus confirming, as already suggested $(9,24)$, that it has inherited of the rDNA locus of only one of its two possible parents: $S$. bayanus. A similar situation was also reported in the case of the mitochondrial genome for which only that of $S$. bayanus was shown to be present in $S$. pastorianus cells $(5,23)$.

A closer relatedness of $S$. pastorianus to $S$. bayanus than to $S$. cerevisiae or $S$. paradoxus was also deduced from analysis of RAPD patterns (13). S. bayanus and $S$. pastorianus also share at least two common physiological characteristics, i.e. an active fructose transport system and a maximum temperature for growth in the range $28-35^{\circ} \mathrm{C}(28)$. Conversely, an active fructose transport system is absent in both $S$. cerevisiae and $S$. paradoxus, both of which have a higher maximum temperature for growth (in the range $35-43^{\circ} \mathrm{C}$ ). These data, together with our results, strongly suggest that if $S$. pastorianus is a natural hybrid between $S$. cerevisiae and $S$. bayanus it is a partial one which has inherited far more genetic material from the latter parent than from the former one. The presence of $S$. cerevisiaespecific DNA sequences in the genome of $S$. pastorianus has been established in the case of some metabolic genes such as $M E T 2$ ( 6 , reviewed by 9$)$.

The study of rDNA spacers has led to the discrimination of two well-separated clusters within which some polymorphism does exist between the yeast strains. However well-separated the 'cerevisiae' and 'bayanus' clusters may be, they consist of very closely related yeasts when the whole genus Saccharomyces is considered $(7,11,12,13)$. Thus, a phylogenetic tree based on the $18 \mathrm{~S}$ gene sequences of species belonging to Saccharomyces and related genera showed that the genus Saccharomyces is very heterogeneous, whereas the species of the Saccharomyces sensu stricto complex form a natural group quite separated from other Saccharomyces and non-Saccharomyces species examined (7). Another example is given by the ori-rep-tra mitochondrial sequence, cloned from $S$. cerevisiae, which, when used as a probe, hybridizes to the DNA of $S$. cerevisiae as well as to $S$. bayanus, $S$. paradoxus and $S$. pastorianus, but not to the DNA of any of six other species of the yeast genus Saccharomyces: Saccharomyces castellii, Saccharomyces dairensis, Saccharomyces exiguus, Saccharomyces kluyveri, Saccharomyces servazzi and Saccharomyces unisporus (26). This was also observed when we attempted to align the ITS sequence of $S$. cerevisiae to that of $S$. kluyveri (GenBank accession no. U09328), the only one available in the databases (R. Messner, H. Prillinger, M. Ibl \& G. Himmler, unpublished). If only ITS 2 is considered, the sequences of all the yeasts of the two 'cerevisiae' and 'bayanus' clusters could be perfectly aligned with only 
10 variable positions among the 220 nucleotides. To align the same sequence of $S$. kluyveri to that of $S$. cerevisiae or $S$. bayanus, it is necessary to create in the former two large gaps of about 20 bases each and only about $65 \%$ of the remaining positions can be aligned.

We extended the PCR-RFLP study to a collection of 26 wine yeast strains assigned to the $S$. cerevisiae sensu stricto group on the basis of traditional phenotypic characters. The rDNA spacer sequences of these strains were distributed in either of the two clusters 'cerevisiae' or 'bayanus'. For most of the strains, this classification was in disagreement with the original identification (Table 2), thus confirming the unsuitability of the classical taxonomic criteria within the $S$. cerevisiae sensu stricto group. However, these results are in perfect agreement with those reported by Naumov et al. (16), who performed genetic crosses and electrophoretic karyotypes on six of the strains we studied (nos 1, 3, 5, 7, 8 and 10). Unexpectedly, a lower level of RFLP was detected in the rDNA spacers of the wine yeast strains, included in either of the two clusters, compared to the polymorphism revealed between the corresponding sequences of the type strains (Fig. 1). A possible explanation could be that a limited number of lineages have adapted to the grape must or, alternatively, that the wine yeasts studied have been isolated over a short period of time in a limited number of sites all located in France as opposed to the varied origins of the type strains.

In conclusion, the analysis of polymorphisms within the rDNA spacers demonstrates that the species of the Saccharomyces sensu stricto group are clearly distributed in two well-separated clusters which have recently diverged from one another as judged by the high similarities between their ITS sequences. This result also clearly shows that the study of rDNA spacer polymorphisms is a valuable tool to infer the phylogenetic position of very closely related yeasts.

\section{ACKNOWLEDGEMENTS}

We would like to thank Dr C. Cuinier (Institut Technique de la Vigne et du Vin, Tours, France) for providing the wine yeast strains. This work was supported by the Centre d'Analyse Moléculaire de la Biodiversité (Université Lyon I) and by a BQR grant of the Université Lyon I.

\section{REFERENCES}

1. Barnett, J. A. (1992). The taxonomy of the genus Saccharomyces Meyen ex Reess: a short review for nontaxonomists. Yeast 8, 1-23.

2. Cardinali, G. \& Martini, A. (1994). Electrophoretic karyotypes of authentic strains of the sensu stricto group of the genus Saccharomyces. Int J Syst Bacteriol 44, 791-797.

3. Galtier, N., Gouy, M. \& Gautier, C. (1996). SEAVIEW and PHYLO_WIN: two graphic tools for sequence alignment and molecular phylogeny. Comput Appl Biosci 12, 543-548.

4. Gryta, H., Debaud, J. C., Effosse, A., Gay, G. \& Marmeisse, R. (1997). Fine-scale structure of populations of the ecto- mycorrhizal fungus Hebeloma cylindrosporum in coastal sand dune forest ecosystems. Mol Ecol 6, 353-364.

5. Guillamon, J., Barrio, M. E., Huerta, T. \& Querol, A. (1994). Rapid characterization of four species of the Saccharomyces sensu stricto complex according to mitochondrial DNA patterns. Int J Syst Bacteriol 44, 708-714.

6. Hansen, J. \& Kielland-Brandt, M. C. (1994). Saccharomyces carlsbergensis contains two functional MET2 alleles similar to homologues from $S$. cerevisiae and $S$. monacensis. Gene 140, 33-40.

7. James, S. A., Cai, J., Roberts, I. N. \& Collins, M. D. (1997). A phylogenetic analysis of the genus Saccharomyces based on 18S rRNA gene sequences: description of Saccharomyces kunashirensis $\mathrm{sp}$. nov. and Saccharomyces martiniae sp. nov. Int $J$ Syst Bacteriol 47, 453-460.

8. Kaneko, Y. \& Banno, I. (1991). Reexamination of Saccharomyces bayanus strains by DNA/DNA hybridization and electrophoretic karyotyping. IFO (Inst Ferment (Osaka)) Res Commun 15, 31-41.

9. Kielland-Brandt, M. C., Nilsson-Tillgren, T., Gjermansen, C., Holmberg, S. \& Pedersen, M. B. (1995). Genetics of brewing yeasts. In The Yeasts, vol. 6, 2nd edn, pp. 223-254. Edited by A. E. Wheals, A. H. Rose \& J. S. Harrison. London: Academic Press.

10. Kimura, M. (1980). A simple method for estimating evolutionary rates of base substitutions through comparative studies of nucleotide sequences. $J \mathrm{Mol}$ Evol 16, 111-120.

11. Messner, R. X. \& Prillinger, M. (1995). Saccharomyces species assignment by long range ribotyping. Antonie Leeuwenhoek 67, 363-370.

12. Molina, F. I., Inoue, T. \& Jong, S. C. (1992). Ribosomal DNA restriction analysis reveals genetic heterogeneity in $\mathrm{Sac}$ charomyces cerevisiae Meyen ex Hansen. Int J Syst Bacteriol 42, 499-502.

13. Molnar, O., Messner, R., Prillinger, M., Stahl, U. \& Slavikova, E. (1995). Genotypic identification of Saccharomyces species using random amplified polymorphic DNA analysis. Syst Appl Microbiol 18, 136-145.

14. Naumov, G. I. (1986). Genetic differentiation and ecology of yeast Saccharomyces paradoxus Batschinskaya. Dokl Akad Nauk SSSR 291, 754-757.

15. Naumov, G. I., Naumova, E. S., Azbukina, Z. M., Korhola, M. \& Gaillardin, C. (1993). Genetic and karyotypic identification of Saccharomyces yeasts from far east Asia. Cryptogam Mycol 14, 85-93.

16. Naumov, G. I., Naumova, E. S. \& Gaillardin, C. (1993). Genetic and karyotypic identification of wine Saccharomyces bayanus yeasts isolated in France and Italy. Syst Appl Microbiol 16, 274-279.

17. Naumov, G. I., Naumova, E. S. \& Korhola, M. (1992). Genetic identification of natural Saccharomyces sensu stricto yeasts from Finland, Holland and Slovakia. Antonie Leeuwenhoek 61, 237-243.

18. Naumov, G. I., Naumova, E. S., Lantto, R. A., Louis, E. J. \& Korhola, M. (1992). Genetic homology between Saccharomyces cerevisiae and its sibling species $S$. paradoxus and $S$. bayanus: electrophoretic karyotypes. Yeast 8, 599-612.

19. Naumov, G. I., Naumova, E. S., Sancho, E. D. \& Korhola, M. (1993). Taxogenetics of the Saccharomyes sensu stricto yeasts from western and south Africa. Cryptogam Mycol 14, 263-270.

20. Naumov, G. I., Naumova, E. S., Turakainen, H. \& Korhola, M. 
(1996). Identification of the $\beta$-galactosidase MEL genes in some populations of Saccharomyces cerevisiae: a new gene MEL11. Genet Res 67, 101-108.

21. Nei, M. \& Li, W. H. (1979). Mathematical model for studying genetic variation in terms of restriction endonuclease. Proc Natl Acad Sci USA 76, 5269-5273.

22. Ness, F. \& Aigle, M. (1995). RTM1: a member of a new family of telomeric repeated genes in yeast. Genetics $\mathbf{1 4 0}$, 945-956.

23. Petersen, R. F., Groth, C., Nilsson-Tillgren, T. \& Piskur, J. (1997). Structural dynamics of the nuclear and mitochondrial genomes within the genus Saccharomyces. Yeasts 13, S71.

24. Petersen, J. G. L., Nilsson-Tillgren, T., Kielland-Brandt, M. C., Gjermansen, C. \& Holmberg, S. (1987). Structural heterozygosis at genes ILV2 and ILV5 in Saccharomyces carlsbergensis. Curr Genet 12, 167-174.

25. Phillipsen, P., Stotz, A. \& Scherf, M. (1991). DNA of Saccharomyces cerevisiae. Methods Enzymol 194, 169-182.

26. Piskur, J., Mozina, S. S., Stenderup, J. \& Pedersen, M. Z. (1995). A mitochondrial molecular marker, ori-rep-tra for differentiation of yeast species. Appl Environ Microbiol 61, 2780-2782.

27. Raué, H. A. \& Planta, R. J. (1991). Ribosome biogenesis in yeast. Nucleic Acids Res Mol Biol 41, 89-129.

28. Rodrigues De Sousa, M., Madeira-Lopes, A. \& SpencerMartins, I. (1995). The significance of active fructose transport and maximum temperature for growth in the taxonomy of Saccharomyces sensu stricto. Syst Appl Microbiol 18, 44-51.

29. Saitou, N. \& Nei, M. (1987). The neighbor-joining method: a new method for reconstructing phylogenetic trees. $\mathrm{Mol}$ Biol Evol 44, 406-425.

30. Sanger, F., Nicklen, S. \& Coulson, A. R. (1977). DNA sequencing with chain-terminating inhibitors. Proc Natl Acad Sci USA 74, 5463-5467.

31. Sequerra, J., Marmeisse, R., Valla, G., Normand, P., Capellano, A. \& Moiroud, A. (1997). Taxonomic position and intraspecific variability of the nodule forming Penicillium nodositatum inferred from RFLP analysis of the ribosomal intergenic spacer and random amplified polymorphic DNA. Mycol Res 101, 465-472.

32. Thompson, J. D., Higgins, D. G. \& Gibson, T. J. (1994). CLUSTAL W: Improving the sensitivity of progressive multiple sequence alignment through sequence weighting, position specific gap penalties and weight matrix choice. Nucleic Acids Res 22, 4673-4680.

33. van der Walt, J. P. (1970). Saccharomyces Meyen emend. Reess. In The Yeasts: a Taxonomic Study, 2nd edn, pp. 555-718. Edited by E. Lodder. Elsevier: Amsterdam.

34. Van Nues, R. W., Rientjes, J. M. J., Van Der Sande, C. A. F. M., Zerp, S. F., Sluiter, C., Venema, J., Planta, R. J. \& Raué, H. A. (1994). Separate structural elements within internal transcribed spacer 1 of Saccharomyces cerevisiae precursor ribosomal RNA direct the formation of $17 \mathrm{~S}$ and $26 \mathrm{~S}$ rRNA. Nucleic Acids Res 22, 912-919.

35. Vaughan Martini, A. (1989). Saccharomyces paradoxus comb. nov., a newly separated species of the Saccharomyces sensu stricto complex based upon $\mathrm{nDNA} / \mathrm{nDNA}$ homologies. Syst Appl Microbiol 12, 179-182.

36. Vaughan Martini, A. \& Kurtzman, C. P. (1985). Deoxyribonucleic acid relatedness among species of the genus Saccharomyces sensu stricto. Int J Syst Bacteriol 35, 508-511.

37. Vaughan Martini, A. \& Martini, A. (1987). Three newly delimited species of Saccharomyces sensu stricto. Antonie Leeuwenhoek 53, 77-84.

38. Vaughan Martini, A., Martini, A. \& Cardinali, G. (1993). Electrophoretic karyotyping as a taxonomic tool in the genus Saccharomyces. Antonie Leeuwenhoek 63, 145-156.

39. White, T. J., Bruns, T., Lee, S. \& Taylor, J. (1990). Amplification and direct sequencing of fungal ribosomal RNA genes for phylogenetics. In PCR Protocols: a Guide to Methods and Applications, pp. 129-141. Edited by M. A. Innis, D. H. Gelfand, J. S. Sninsky \& T. J. White. Academic Press: New York.

40. Yarrow, D. (1984). Saccharomyces Meyen ex. Reess. In The Yeasts: a Taxonomic Study, 3rd edn, pp. 379-395. Edited by N. J. W. Kreger-van Rij. Elsevier: Amsterdam. 